\title{
Topic Modelling of Tourist Dining Experiences Based on the GLOBE Model
}

\author{
Roman Egger (D), Angela Pagiri, Barbara Prodinger ${ }^{(凶)}$, Ruihong Liu, \\ and Fabian Wettinger
}

University of Applied Sciences Salzburg, Puch/Salzburg, Austria

roman.egger@fh-salzburg.ac.at,

prodinger_barbara@gmx.at

\begin{abstract}
The needs of travellers vary across cultures. When it comes to culinary aspects, there is a strong connection between gastronomy and culture. To optimise service offerings, investigation of the essential aspects of dining experiences in relation to cultural backgrounds is of great importance. In the age of digitalisation, tourists share their dining experiences throughout their multiphasic travel journey via online platforms. By considering nine distinct cultural backgrounds, this research aims to investigate tourist experiences based on TripAdvisor restaurant reviews through topic modelling, using the city of Salzburg as its study context. Depending on one's cultural circumstances, the findings demonstrate that the most important aspects include staff, food-menu items, value for money, restaurant physical appearance, food authenticity, overall service, menu offers, food quality, atmosphere, and recommendations. This study advances the state-of-the-art knowledge of societal culture as a variable in the target market analysis of restaurant customers. Findings allow restaurant owners, other tourism service providers, and destination management organisations to analyse and adapt their service offerings and strategies accordingly.
\end{abstract}

Keywords: TripAdvisor $\cdot$ Dining experience $\cdot$ Societal culture $\cdot$ GLOBE

\section{Introduction}

Visitors from different countries vary in their service expectations and travel behaviours due to cultural backgrounds, which subsequently influences their travel experience $[1,2]$. Thus, identifying those needs is essential in order to contribute to up-todate services and products [3]. Literature has provided insights on service quality and customer satisfaction in a restaurant setting based on widely used models such as SERVQUAL [4] and DINESERV [5, 6]. However, in this process, guests fill out a predefined questionnaire before and after the service, leading to mostly small sample sizes caused by the challenge of persuading guests to participate [7].

Seeing that the rapid development of information and communication technologies allows visitors to share their experiences in the form of user-generated content (UGC) on various online platforms [8], researchers and marketers can take this as a valuable opportunity since these technologies facilitate deeper access to a broad range 
of insightful data [9]. For instance, existing studies have examined TripAdvisor reviews to define the sentiment of customers' feelings towards dining experiences [10] and online ratings on Yelp to uncover different motivations as well as the satisfaction of customers coming from the USA and China [11]. Such investigations refer to predefined themes from existing service quality models to unveil customers' feelings, satisfaction, or perception of a dining experience and then correlate it to countries or continents. A worldwide cross-cultural comparison is, however, widely missing. Hence, this research seeks to contribute to the field of dining experiences by analysing online reviews from a bottom-up approach in order to discover which aspects of the dining experience are critical for visitors in relation to their cultural backgrounds.

To achieve the stated objectives, this study adopted the city of Salzburg as its research context for the following reasons: Salzburg ranked first on the "Best in Travel 2020" list of the world's most attractive cities thanks to its historical sightseeing spots and local cuisine [12]. In the summer season of 2019, nearly 2 million arrivals and more than 3 million overnight stays were recorded in the city of Salzburg. In addition, Salzburg attracts international visitors from a wide variety of countries, including Germany, followed by the Netherlands, Arab countries, Czech Republic and USA [13], currently gaining momentum again after the COVID-19 pandemic. In this study, we apply a mixed method approach by conducting data visualisation, data mining, and topic modelling techniques, to transform unstructured online reviews into interpretable patterns.

\section{Literature Review}

\subsection{Tourist Dining Experience}

During this era of the experience economy [14], businesses should design their products and services while also taking into consideration the full range of effects that can be evoked from an interaction between consumers and service offerings [15]. This is particularly important in the tourism and hospitality industry, which is heavily based on experiences [16]. In the context of restaurants, scholars have established different service quality models to identify elements that are influential to customers' satisfaction and experiences, among which the SERVQUAL instrument represents the most widely used model [4]. More specifically, service quality is evaluated based on five dimensions, namely, reliability, responsiveness, assurance, empathy, and tangibles [4]. Despite its popularity, the SERVQUAL model was primarily developed for banks as well as credit card, repair, maintenance, and telephone companies [4]. Therefore, since scale items should be adjusted to fit specific industries [17], scholars subsequently developed the DINESERV model so as to investigate visitors' expectations of quickservice, fine-dining, and casual-dining businesses [18].

A modified version of the DINESERV model showcases further factors of customers' expectations and perceptions at restaurants. The implementation of the overall categories, price and satisfaction, explains customers' thoughts on paying more than expected and the price of food items, while the satisfaction of the dining experience can be confirmed through customers revisiting the restaurant and in the recommendation 
itself. Other tangible factors include a clean parking area and nice building exterior, restaurant decoration, easily readable menu, comfortable seating, clean dining area, and neat staff [7]. Concerning the environment, evaluation of physical and human surroundings in a restaurant emphasises the aesthetics of the facility, ambiance, table setting, lighting, and the service staff [19]. Moreover, current literature reinforces that, in order to achieve high customer satisfaction, the interaction between customers and employees should not be overlooked [20]. In addition to the service itself, beverage and food attributes are also found to be critical factors in relation to customer fulfilment and post-dining behavioural intention [21]. Today, tourists have more opportunities to share their holiday experiences on social networks [10], allowing individuals to express their thoughts and opinions and make them accessible to the online global community [22] via review platforms such as TripAdvisor. Not only do these review platforms play a key role in tourists' decision-making processes [23], but they also provide managers with a tremendous amount of data that can be used to better understand customers [10] through advanced text mining techniques [24]. A recent study, for instance, explored customers' feelings shared on TripAdvisor when dining in local restaurants [10]. The importance of location and service quality was explored using topic modelling; however, such experiences cannot be standardised, nor do they apply to everyone. Albeit the significance of acknowledging that expectations regarding food, environment, and interpersonal interaction vary across cultures [11], understanding customer experiences from different countries remains scarce.

\subsection{Cultural Dimensions and Clusters}

To classify people with different cultural backgrounds, one of the most common approaches is based on Hofstede's cultural dimensions theory [25]. This cross-cultural communication framework covers the dimensions of individualism-collectivism, uncertainty avoidance, power distance, masculinity-femininity, and long-/short-term orientation. Subsequently, other researchers modified and transformed the Hofstede model into the GLOBE model [26, 27], with the dimensions uncertainty avoidance (fear of ambiguity), power distance (acceptance of an unequal distribution of power), institutional collectivism (more validation of broad societal interests than of individual goals), in-group collectivism (loyalty towards families and organisations), gender egalitarianism (equal treatment of genders), assertiveness (level of directness, forcefulness, or aggression), future orientation (planning, delaying gratification), performance orientation (appreciation for setting and reaching goals), and humane orientation (fairness, generosity, kindness) [26, 28, 29]. In order to make the GLOBE model applicable for practical use in multinational societies, a model of regional clusters across the world was developed as well. The clusters and their characteristics [28] are outlined in Table 1 below. 
Table 1. The GLOBE model.

\begin{tabular}{|c|c|c|}
\hline Cluster & Country & Characteristics \\
\hline Anglo & $\begin{array}{l}\text { Canada, USA, Australia, Ireland, } \\
\text { England, South Africa (white } \\
\text { sample), and New Zealand }\end{array}$ & $\begin{array}{l}\text { High in performance orientation; low } \\
\text { in in-group collectivism }\end{array}$ \\
\hline $\begin{array}{l}\text { Confucian } \\
\text { Asia }\end{array}$ & $\begin{array}{l}\text { Singapore, Hong Kong, Taiwan, } \\
\text { China, South Korea, and Japan }\end{array}$ & $\begin{array}{l}\text { High in performance orientation, } \\
\text { institutional, in-group collectivism }\end{array}$ \\
\hline $\begin{array}{l}\text { Eastern } \\
\text { Europe }\end{array}$ & $\begin{array}{l}\text { Greece, Hungary, Albania, Slovenia, } \\
\text { Poland, Russia, Georgia, and } \\
\text { Kazakhstan }\end{array}$ & $\begin{array}{l}\text { High in assertiveness, in-group } \\
\text { collectivism, gender egalitarianism; } \\
\text { low in performance orientation, future } \\
\text { orientation, uncertainty avoidance }\end{array}$ \\
\hline $\begin{array}{l}\text { Germanic } \\
\text { Europe }\end{array}$ & $\begin{array}{l}\text { Austria, The Netherlands, } \\
\text { Switzerland (German speaking), and } \\
\text { Germany }\end{array}$ & $\begin{array}{l}\text { High in performance orientation, } \\
\text { assertiveness, future orientation, } \\
\text { uncertainty avoidance; low in humane } \\
\text { orientation, institutional, and in-group } \\
\text { collectivism }\end{array}$ \\
\hline $\begin{array}{l}\text { Latin } \\
\text { America }\end{array}$ & $\begin{array}{l}\text { Ecuador, El Salvador, Colombia, } \\
\text { Bolivia, Brazil, Guatemala, } \\
\text { Argentina, Costa Rica, Venezuela, } \\
\text { and México }\end{array}$ & $\begin{array}{l}\text { High in in-group collectivism; low in } \\
\text { performance orientation, institutional } \\
\text { collectivism, future orientation, } \\
\text { uncertainty avoidance }\end{array}$ \\
\hline $\begin{array}{l}\text { Latin } \\
\text { Europe }\end{array}$ & $\begin{array}{l}\text { Israel, Italy, Switzerland } \\
\text { (Francophone + Italian speaking), } \\
\text { Spain, Portugal, and France }\end{array}$ & $\begin{array}{l}\text { Mostly moderate scores in } \\
\text { dimensions, low in humane } \\
\text { orientation and institutional } \\
\text { collectivism }\end{array}$ \\
\hline $\begin{array}{l}\text { Middle } \\
\text { East }\end{array}$ & $\begin{array}{l}\text { Turkey, Kuwait, Egypt, Morocco, } \\
\text { and Qatar }\end{array}$ & $\begin{array}{l}\text { High in in-group collectivism, low in } \\
\text { future orientation, gender } \\
\text { egalitarianism, and uncertainty } \\
\text { avoidance }\end{array}$ \\
\hline $\begin{array}{l}\text { Nordic } \\
\text { Europe }\end{array}$ & Denmark, Finland, and Sweden & $\begin{array}{l}\text { High in future orientation, gender } \\
\text { egalitarianism, institutional } \\
\text { collectivism, and uncertainty } \\
\text { avoidance; low in assertiveness, } \\
\text { power distance }\end{array}$ \\
\hline $\begin{array}{l}\text { Southern } \\
\text { Asia }\end{array}$ & $\begin{array}{l}\text { Philippines, Indonesia, Malaysia, } \\
\text { India, Thailand, and Iran }\end{array}$ & $\begin{array}{l}\text { High in humane orientation and in- } \\
\text { group collectivism }\end{array}$ \\
\hline $\begin{array}{l}\text { Sub- } \\
\text { Saharan } \\
\text { Africa }\end{array}$ & $\begin{array}{l}\text { Zimbabwe, Namibia, Zambia, } \\
\text { Nigeria, and South Africa (black } \\
\text { sample) }\end{array}$ & High score in humane orientation \\
\hline
\end{tabular}

\section{Methodology}

\subsection{Study Context}

The city of Salzburg thrives from the tremendous amount of income generated by the gastronomy branch, with over 3,502 culinary businesses currently running in Salzburg [30]. Thus, with highly concentrated tourists, this destination offers sufficient data for 
this study to explore tourists' perceptions of dining experience from different cultural backgrounds by mining their content with regards to travel expectations, motivations, and satisfaction on TripAdvisor.

\subsection{Data Collection, Pre-processing, and Analysis}

The web scraping software Octoparse was used to collect restaurant reviews and attributes from TripAdvisor. Restaurant attributes include names, review content, restaurant URLs, published dates and reviewers' locations. All available restaurant reviews, written in English, from the city of Salzburg were scrapped, resulting in 27,626 reviews. This study selected only reviews published between May 1 and October 30, 2019, leading to a total of 1,901 reviews. This timeframe was chosen because of school holidays within and around Austria, where high tourism activities take place, and to view data before the outbreak of the COVID-19 pandemic. Afterward, based on reviewers' nationalities, all reviews were classified into different cultural clusters according to the GLOBE model. Customers who did not disclose their locations on TripAdvisor were removed, resulting in a final dataset consisting of 1,461 reviews.

Next, Orange 3, an open-source machine learning toolkit, was applied for data preprocessing and analysis. To transform unstructured reviews into structured forms for analysis [31], the following three steps were conducted: (1) tokenizing texts and turning all the text into lowercase, (2) removing punctuations, numbers, stop words, and, in addition to general stop words, a list of custom stop words specifically developed for this study, and, lastly, (3) normalising words by removing suffixes.

In order to discover hidden topics in online reviews, this study applied Latent Dirichlet Allocation (LDA), one of the most popular topic modelling techniques in tourism and hospitality [32]. LDA was conducted on each of the cultural clusters so as to uncover a corresponding set of attributes or themes through the corpus-based guest reviews. To determine the number of topics in each cluster, multidimensional scaling was applied to analyse each topic's distance between each other and to investigate duplicate or recurring topics. Thus, different clusters yielded various numbers of topics. Finally, a list of keywords, which represent a topic in the topic modelling process, was used as a reference for labelling its representative topics. Subsequently, the extracted keywords of the respective geographical areas were vectorised using document embedding (fastText), followed by a dimensional reduction using tSNE (Perplexity $=15$, Exaggeration $=1$, PCA components $=25$, Normalised Data, and preserved global structure) in order to visualise the GLOBE spaces. The optimal tSNE hyperparameters were chosen after a visual inspection with the Tensorboard Embedding Projector. 


\section{Findings}

\subsection{Overview of the Topic Modelling Results}

Table 2 outlines the ten identified topics generated from LDA for a total of nine cultural clusters, as the Sub-Saharan Africa cultural cluster was dropped due to scarce data sampling.

Table 2. Identified topics per cultural cluster.

\begin{tabular}{|c|c|c|}
\hline Cluster & $\mathrm{n}$ & Identified topics \\
\hline Anglo & 924 & $\begin{array}{l}\text { (1) Staff, (2) Food Menu Item, (3) Restaurant Physical Appearance, } \\
\text { (4) Recommendation }\end{array}$ \\
\hline $\begin{array}{l}\text { Confucian } \\
\text { Asia }\end{array}$ & 34 & (1) Value for Money, (2) Staff, (3) Food Authenticity \\
\hline $\begin{array}{l}\text { Eastern } \\
\text { Europe }\end{array}$ & 68 & $\begin{array}{l}\text { (1) Staff, (2) Food Authenticity, (3) Food Menu Item, (4) Value for } \\
\text { Money }\end{array}$ \\
\hline $\begin{array}{l}\text { Germanic } \\
\text { Europe }\end{array}$ & 153 & $\begin{array}{l}\text { (1) Restaurant Physical Appearance, (2) Staff, Menu Offers, (3) Food } \\
\text { Quality }\end{array}$ \\
\hline $\begin{array}{l}\text { Latin } \\
\text { America }\end{array}$ & 21 & (1) Food Authenticity, (2) Menu Offers \\
\hline $\begin{array}{l}\text { Latin } \\
\text { Europe }\end{array}$ & 73 & (1) Value for Money, (2) Overall Service, (3) Food Menu Item \\
\hline Middle East & 32 & (1) Food Menu Item, (2) Staff, (3) Recommendation \\
\hline $\begin{array}{l}\text { Nordic } \\
\text { Europe }\end{array}$ & 45 & $\begin{array}{l}\text { (1) Overall Service, (2) Food Quality, (3) Menu Offers, } \\
\text { (4) Atmosphere }\end{array}$ \\
\hline $\begin{array}{l}\text { Southern } \\
\text { Asia }\end{array}$ & 111 & $\begin{array}{l}\text { (1) Restaurant Physical Appearance, (2) Food Menu Item, (3) Value } \\
\text { for Money, (4) Overall Service, (5) Staff }\end{array}$ \\
\hline
\end{tabular}

The naming of the topic was based on a list of keywords contributing the most to a specific topic. Additional topics/themes were also added due to a prevalent theme, which had not been previously found via topic modelling, being discovered in the reviews. Yet, it is important to note that the number of reviews was not equally distributed and may have influenced the number of the extracted topics. Overall, Staff, Food Menu Item, and Value for Money presented themselves as the top aspects when tourists shared their dining experience.

\subsection{Topic Modelling Results per Cultural Cluster}

The topics per cultural cluster shown in Table 2 are based on up to 5000 keywords. Figure 1 shows the topics per cultural cluster after tSNE dimensionality reduction and locates them on a map. Interestingly, the word embeddings of these keywords reflect the proximity of the individual GLOBE spaces very well. As such, the two Asian clusters can be seen grouped very close to each other on the left side, while the Middle East is strongly separated from all other areas on the bottom left, and the Anglo- 
American area on the opposite top right is also entirely homogeneous. In between, Latin Europe and Latin America are separated but in close proximity, and the European regions are somewhat mixed but still clearly recognisable. This confirms that the cultural features described in detail below can indeed be clearly teased apart from each other and can be perceived as their respective typical characteristic.

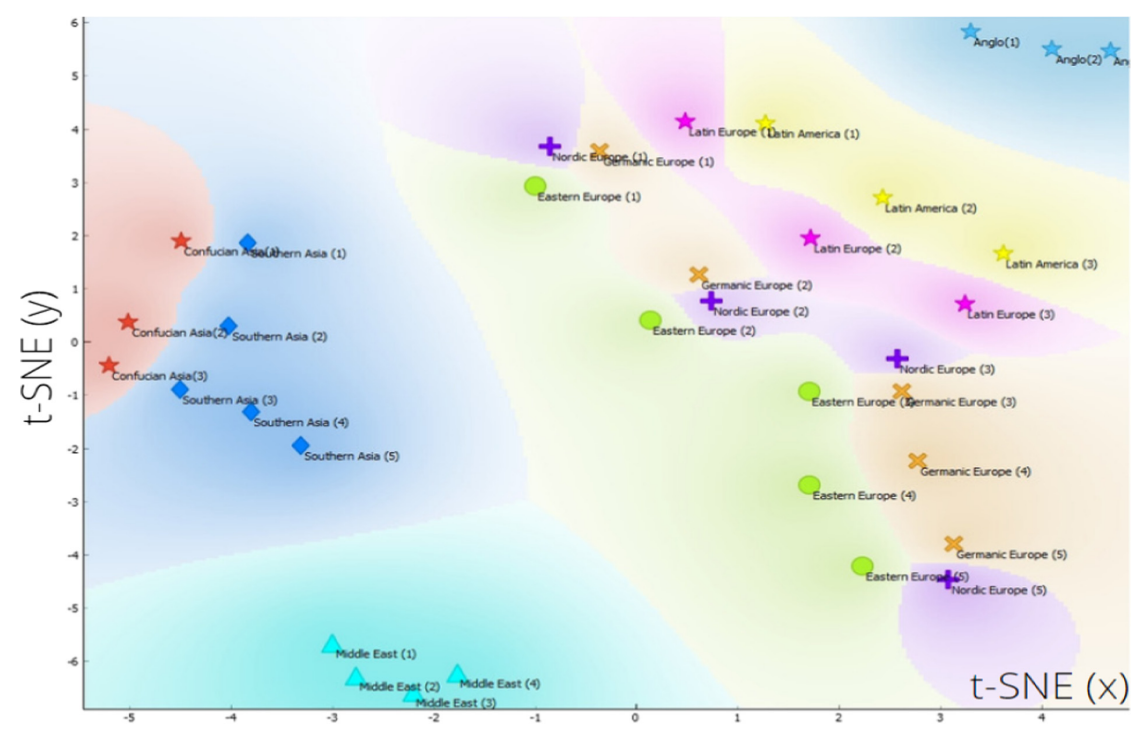

Fig. 1. Topic keywords word embedding across GLOBE cultures

\section{Anglo}

For Anglo cluster, the staff plays an important role which can be seen from several comments (e.g., "The chef was very accommodating to our gluten free needs" and "The staff was friendly and attentive"). Food menu items display a high degree of significance and seen to be followed with critiques and recommendations such as "Choice of 3 dishes, had the sardine pasta, and it was fantastic". This observation is consistent with the GLOBE Model findings of the Anglo cluster which possess a highperformance orientation, showing appreciation for an achieved standard. This cluster is attentive to a restaurant's physical setting which shares similarities with the Southern Asian cluster. Different from the Southern Asian cluster, the Anglo finds the restaurant setting and location more important than the décor, which is represented by (e.g., "We ate outside and had a delightful dinner" and "Not too far from the centre of the city").

\section{Confucian Asia}

For this cluster, value for money is an important aspect, observed in "We think the pricing of the food was reasonable". This characteristic is similar to the Southern Asia cluster, where the price paid outweigh the food portion. Also, Staff is considered an integral part, proved by "The owner is very friendly". Congruent with the GLOBE model, the performance orientation, more specifically, their deliberate expression of 
appreciation to the staff seems up to par. Meanwhile, food authenticity is another prevalent factor, which can be observed in the excerpts: "We went there for dinner and food is good traditional Austrian" and "Very authentic and delicious Korean food!". It is worth noting that, interestingly, Confucian Asian tend to search for their own culture's cuisine, and it should also meet their authenticity expectation. This is consistent with the GLOBE model's high score of institutional and in-group collectivism, by showing loyalty to their own origins despite being outside of their home country.

\section{Southern Asia}

This cluster considers the physical restaurants appearance most important, emphasising on the decor or interior, as seen in "richly decorated" and "friendly US-style diner". Food menu items are another prevalent topic which can be seen from the specific mentions of food, such as "Dal Tarka", "Beef Pho", followed by a recommendation to visit, echoing this culture' humane orientation nature. "Reasonable rate" and "value for money" represent value for money aspect, which is also mentioned by the Confucian Asia, Latin Europe, and Eastern Europe. Interestingly, not only the attitude of the staff, but also on the appearance and facial expression is important, (e.g., "Served by a bearded guy with several tattoos" and "The owner around with a very unhelpful angry expression"). Lastly, several dissatisfied expression emerge, "lousy service" and "aggressive staff" in addition to positive experience reviews such as "comfort", "the service was very friendly", and "humble servings".

\section{Eastern Europe}

Interaction with the staff and their friendliness is crucial for this cluster, as seen in: "The waiter in the lounge was very grumpy" and "That manager was very impolite". Notably, the presence of negative reviews towards the staff are in line with the characteristics of assertiveness given in the GLOBE model. Nevertheless, this cluster appreciates food authenticity, "I would recommend it for anyone visiting Salzburg and wants to enjoy a traditional Austrian dish". Food menu items with implicit reference for or against recommending the place also emerge, as seen in: "Very nice options for platters to have with your wine" and "If you are looking for a great schnitzel off the beaten path, this is the place". Finally, value for money is a vital aspect for the Eastern European contrasting with the Asians where price sensitivity outweighs portion generosity, proved in "It's a little pricey but, given the rest of the prices in Salzburg".

\section{Latin America}

For Latin Americans it is important for businesses to deliver their brand promise in terms of (food) authenticity, for example, "Make sure you go to this typical Austrian restaurant. Serve good Austrian food" and "The food is really good. Austrian dishes and drinks". Another salient aspect is the menu offers, e.g. available options, types of drinks, and cuisine types (e.g., "The menu was excellent-it was hard to decide what to order" and "All kind of seafood and in any possible way"). The findings show consistency with GLOBE model in terms of the low score in performance orientation (whether people are rewarded for delivering good performance) due to the fact that important dining aspects revolve around the food itself rather than the staff. 


\section{Germanic Europe}

The appearance and location of restaurants are evidently important aspects for this cluster, as seen in "One of the most modern restaurants in Salzburg" and "The restaurant has a very good flair". This implies that this culture appreciate the comfort and pleasant atmosphere. Concerning the staff, attentiveness and attitude are the most appreciated traits, for instance, "We were greeted by a nice waiter who showed us to our table" exhibiting deliberate expression of appreciation which is congruent with their high performance orientation's GLOBE characteristic. Moreover, menu offers and food quality (e.g. "Excellent meat dishes. Good selection of drinks") are important but inconsistent food availability is not appreciated, as seen in "Limited menu". The quality of the food served in terms of flavour, presentation, and ingredients are also notable, "The creamy spinach was so good and the meat had a high quality".

\section{Latin Europe}

Value for money is the most important aspect, as seen in "Good service at a reasonable price" and "Pizzas are really huge, tasty and at a very good price". Although this is consistent with the Southern Asian and Eastern Europeans, the Latin Europeans emphasise price points rather than the food generosity. Food menu items are mostly followed with a critique, for instance "Burger was good though not amazing" and "We chose white asparagus which was excellent". This cluster recognises service as a significant factor, encompassing larger spectrum of a dining experience: staff-, food-, and restaurant-related, seen in the generality of review contents such as, "The place is nice and the court is a great place, but the food was mediocre (restaurant- and foodrelated)" and "The staff is very friendly and the wiener schnitzel was one of the best we've had (staff- and food-related)".

\section{Nordic Europe}

The overall service (e.g., "service is immaculate", "super service", and "quick service") with a strong focus placed on services provided by the staff emerge, as seen in "The two women who run it are super kind and really cares about their food". The flavour, ingredients, and the presentation thereof are key factors for this cluster, for instance "Traditional food with lots of flavour!". Moreover, menu offers are equally important, proved by frequent references to modern Austrian kitchen, vegetarian food, local wines, home-brewed beer, and gluten-free beer, e.g. "Amazing little beer garden with solid food and amazing home-brewed beer" and "Nice place for some typical Austrian food, gluten-free beer available and a few but very tasty food options". Lastly, the atmosphere is proved to be as important, as seen in "historical environment" and "hidden gem", which is congruent with the GLOBE model's uncertainty avoidance characteristic, since authentic local atmosphere meets this cluster's expectations.

\section{Middle East}

Food menu items are of great significance for this cluster (e.g., "Shrimp pizza at the bar, and it tastes lovely" and "Beautiful wholesome food"). The interaction with the staff is as influential, as seen in "The host has been the perfect one in all way" and "The owner of the restaurant and staff are friendly and accommodative". Recommendations are significant for the Middle Eastern cluster, for instance "We went to this restaurant on recommendation" and "We found this restaurant from TripAdvisor". This finding 
transpires the common practice among Middle Eastern tourists to go to places upon recommendation and correspondingly recommend places to others upon dining satisfaction. In line with the GLOBE model, this aspect displays a certain degree of consistency for high in-group collectivism since, by giving honest opinions about their experiences, this behaviour shows loyalty towards their own family or organisation.

\section{Discussion}

Seeing that various aspects of touristic experiences, such as dining or visiting sights, can be sourced from online review portals, and connections to a place of origin or culture can be drawn from the differences in behaviour [33], this study analyses online restaurant reviews so as to make generalisations regarding different cultures. In this way, when addressing and catering to a certain country or culture, one can resort to a set of recommendations on what specific aspects they tend to pay attention to. Overall, the most important aspects related to customer dining experiences are staff, food menu items, value for money, restaurant physical appearance, food authenticity, overall service, menu offers, food quality, atmosphere, and recommendation.

The study's findings partly differ from the literature in that food was mentioned regularly in reviews, with food even being considered the most important factor for those who enjoy dining. Unlike the dimensions in the SERVQUAL and DINESERV model, which focus more on the interaction between customers and employees rather than the products themselves (e.g., food items), this research is consistent with other scholars who emphasise that attributes of food, regarding the quality, freshness, tastiness, and temperature, are seen as the most influential criteria among customer fulfilment and post-dining behavioural intention [20, 21].

Yet, notably, the priority of these aspects varies across cultures. This study shows that societal cultures can provide valuable insights, e.g., for gastronomy businesses when trying to target a certain market. Moreover, it might aid in guiding employee training, especially in regard to the specific treatment of certain target groups (grooming recommendations, welcoming rituals, etc.). The analysis further reveals that societal culture might be a new variable in market research, especially in target market analysis, in addition to established ones such as demographics and lifestyle milieus. Finally, this study supports results from recent literature, suggesting that machine learning can give valuable insights by processing large amounts of UGC from review sites [33].

To conclude, this study is novel in that cultural background was incorporated, using an established scientific concept, namely, the GLOBE clusters. Different from previous literature focusing on limited cultural groups [33], the findings of this research allows for the generalisation of all regions within a given cluster. By using machine learning and drawing connections to the culture of customers, this study concludes that analysing online restaurant reviews can give valuable insights for professionals in the field. 


\section{Conclusion}

This research contributes to the tourism industry through the use of machine learning techniques, thereby showcasing the possibilities of transforming UGC into structured patterns so as to reveal tourist experiences shared online. As such, the revealed insights provide restaurant managers with the exact gastronomical preferences of their target groups, which, in turn, can be used to optimise business strategies and service offerings. On a wider scale, this study is also beneficial for destination management organisations to promote gastronomy in foreign countries. More specifically, destination marketers now have the opportunity to check the exact aspects of a dining experience that a certain cultural cluster may be interested in and tailor promotional texts, images, and videos accordingly. Ultimately, this research expands upon the existing knowledge of the use of text mining and machine learning to process and analyse large amounts of user-generated data in tourism contexts.

Regardless, this study is not without its limitations. First, the sample was narrowed down to include English reviews only, and the city or country of residence was taken from TripAdvisor. As such, the assumption that a reviewer belongs to a particular cultural cluster is solely based on his/her stated place of residence. Whether or not that region represents their "true" culture, or if they were merely expatriates living in a certain place at that time, cannot be validated. For future research, it is recommended to investigate the preferences of the cultures from where large data density, that represent all 10 GLOBE cultural clusters, can be obtained, for instance major cities e.g. New York or Tokyo. This will increase the robustness of the cultural cluster analysis. Moreover, further studies could explore other aspects of tourism, such as accommodation or attractions, that can benefit from this approach in similar ways.

\section{References}

1. Lonely Planet. https://www.lonelyplanet.com/best-in-travel/cities. Accessed 08 Feb 2021

2. Land Salzburg. https://www.salzburg.gv.at/statistik_/Seiten/statistik-tourismus.aspx. Accessed 10 Aug 2021

3. Li X, Lai C, Harrill R, Kline S, Wang L (2011) When east meets west: an exploratory study on Chinese outbound tourists' travel expectations. Tour Manag 32(4):741-749

4. Kim S, Chung JE, Suh Y (2016) Multiple reference effects on restaurant evaluations: a crosscultural study. IJCHM 28:1441-1466

5. Buhalis D, Law R (2008) Progress in information technology and tourism management: 20 years on and 10 years after the Internet. Tour Manag 29(4):609-623

6. Parasuraman A, Zeithaml VA, Berry L (1988) SERVQUAL: a multiple-item scale for measuring consumer perceptions of service quality. J Retail 64(1):12-40

7. Pikkemaat B, Peters M, Chan CS (2018) Needs, drivers and barriers of innovation: the case of an alpine community-model destination. Tour Manag Perspect 25:53-63

8. Lai IKW, Hitchcock M (2016) A comparison of service quality attributes for stand-alone and resort-based luxury hotels in Macau: 3-dimensional importance-performance analysis. Tour Manag 55:139-159 
9. Marković S, Komsic J, Dorčić J (2015) Measuring service quality in Croatian restaurants: application of DINESERV scale. Marketing Insights from a Changing Environment. Pearson, London, pp 131-161

10. Becken S, Alaei AR, Wang Y (2019) Benefits and pitfalls of using tweets to assess destination sentiment. J Hosp Tour Technol 11:19-34

11. Sigala M, Gretzel U (2017) Advances in Social Media for Travel, Tourism and Hospitality: New Perspectives, Practice and Cases. Routledge, New York

12. Yu CE, Zhang X (2020) The embedded feelings in local gastronomy: a sentiment analysis of online reviews. J Hosp Tour Technol 11(3):461-478

13. Jia S (2020) Motivation and satisfaction of Chinese and U.S. tourists in restaurants: a crosscultural text mining of online reviews. Tour Manag 78:104071

14. Pine BJ, Gilmore JH (2011) The Experience Economy. Harvard Business Press, Boston MA

15. Desmet P, Hekkert P (2007) Framework of product experience. Int J Des 1(1):57-66

16. Yu J, Egger R (2021) Color and engagement in touristic Instagram pictures: a machine learning approach. Ann Tour Res 89:103204

17. Abezie H (2019) Assessing a restaurant service quality using the DINESERV model: a qualitative study on Pizza Hut. Master's Thesis, Umeå University, Umeå

18. Stevens P, Knutson B, Patton M (1995) DINESERV: a tool for measuring service quality in restaurants. Cornell Hotel Restaur Adm Q 36(2):5-60

19. Ryu K, Jang S (2008) DINESCAPE: a scale for customers' perception of dining environments. J Foodserv Bus Res 11(1):2-22

20. Gustafsson IB, Ostrom A, Johansson J, Mossberg L (2006) The five aspects meal model: a tool for developing meal services in restaurants. J Foodserv 17(2):84-93

21. Shariff SNFBA et al (2015) The influence of service quality and food quality towards customer fulfillment and revisit intention. Canadian Soc Sci 11(8):138-144

22. Dellarocas C (2003) The digitization of word of mouth: promise and challenges of online feedback mechanisms. Manage Sci 49(10):1407-1424

23. Gretzel U, Yoo KH (2008) Use and impact of online travel reviews. In: O'Connor P, Höpken W, Gretzel U (eds) Information and Communication Technologies in Tourism 2008. Springer, Vienna, pp 35-46

24. Luo Y, Xu X (2021) Comparative study of deep learning models for analyzing online restaurant reviews in the era of the COVID-19 pandemic. Int J Hosp Manag 94:102849

25. Hofstede G (2003) What is culture? A reply to Baskerville. Acc Organ Soc 28(7-8):811-813

26. House RJ, Javidan M, Hanges PJ, Dorfman PW (2002) Understanding cultures and implicit lead-ership theories across the globe: an introduction to project GLOBE. J World Bus 37 (1):3-10

27. Pagda Z, Bayraktar S, Jimenez A (2021) Exploring culture and leadership after 23 years: a replication of GLOBE project in Turkey. J Int Manag 27(1):100822

28. House RJ, Hanges PJ, Javidan M, Dorfman PW, Gupta V (2004) Culture, Leadership, and Organizations: The GLOBE Study of 62 Societies. SAGE Publications, Thousand Oaks

29. Javidan M, Dorfman PW, De Luque MS, House RJ (2006) In the eye of the beholder: cross cultural lessons in leadership from project GLOBE. Acad Manag Perspect 20(1):67-90

30. Austrian Economic Chambers. https://www.wko.at/branchen/tourismus-freizeitwirtschaft/ tourismus-freizeitwirtschaft-in-zahlen-2019.pdf. Accessed 10 Aug 2021

31. Han HJ, Mankad S, Gavirneni N, Verma R (2016) What guests really think of your hotel: text analytics of online customer reviews. Cornell Hosp Rep 16(2):3-17 
32. Arefieva V, Egger R, Yu J (2021) A machine learning approach to cluster destination image on Instagram. Tour Manag 85:104318

33. Wang L, Kirilenko AP (2021) Do tourists from different countries interpret travel experience with the same feeling? Sentiment analysis of TripAdvisor reviews. Inf Commun Technol Tour 2021:294-301

Open Access This chapter is licensed under the terms of the Creative Commons Attribution 4.0 International License (http://creativecommons.org/licenses/by/4.0/), which permits use, sharing, adaptation, distribution and reproduction in any medium or format, as long as you give appropriate credit to the original author(s) and the source, provide a link to the Creative Commons license and indicate if changes were made.

The images or other third party material in this chapter are included in the chapter's Creative Commons license, unless indicated otherwise in a credit line to the material. If material is not included in the chapter's Creative Commons license and your intended use is not permitted by statutory regulation or exceeds the permitted use, you will need to obtain permission directly from the copyright holder. 